\title{
Éramos pocos y la abuela contrajo el coronavirus. Boceto sobre la coyuntura latinoamericana Covid-19
}

\author{
Waldo Ansaldi ${ }^{2}$ \\ waldoansaldi@gmail.com \\ Universidad de Buenos Aires
}

\begin{abstract}
Estamos al borde de un precipicio: miramos el abismo, sentimos malestar y vértigo. Nuestro primer impulso es retroceder ante el peligro. Inexplicablemente, nos quedamos.
\end{abstract}

Edgar Allan Poe, El demonio de la perversidad

Resumen: El artículo es un esbozo de cuestiones a tener en cuenta para un posterior análisis pormenorizado, extenso y cuidadoso de la actual coyuntura política latinoamericana, caracterizada por un notable y agresivo avance de las posiciones de derecha en todos los ámbitos sociales. En términos de ejercicio del poder se aprecia la elección del formato de representación institucional capitalista, como en los inicios del ascenso de la burguesía como clase. Ese ejercicio del poder se realiza en un contexto planetario dominado por el patrón de acumulación del capital basado en la valorización financiera y el simultáneo desarrollo de la crisis-señal del ciclo sistémico de acumulación norteamericano. $Y$ ba producido una formidable distribución desigual de la riqueza que, más que miedo $y / u$ odio, muestra en el comportamiento de clase de la burguesía una formidable indiferencia por la vida de la mayoría de la población mundial. Ese comportamiento, cuya expresión más brutal es el deseo de la muerte de "los otros", se expresa mayoritariamente de manera genérica, pero en ocasiones se refiere a individuos concretos. Significativamente, va acompañado del peso creciente de las iglesias evangélicas, particularmente entre las clases populares. La pandemia de la COVID-19 ba puesto de manifiesto los límites del modelo capitalista vigente y ba

\footnotetext{
1 Este artículo expone los resultados parciales alcanzados en la investigación "Derechas, neoliberalismo y hegemonía cultural en América Latina en el siglo xxI”, Programación UBACYT 2018-2020, dirigida por la Dra. Verónica Giordano.

2 Universidad de Buenos Aires, Facultad de Ciencias Sociales, Instituto de Estudios de América Latina y el Caribe. Universidad Nacional de Córdoba, Facultad de Ciencias Sociales, coordinador académico de la Línea Sociología del Doctorado en Estudios Sociales de América Latina.
} 
generado las primeras manifestaciones de lo que se supone vendrá una vez superada. El autor propone cautela y proseguir con los análisis antes de hacer pronósticos.

Palabras clave: coyuntura; América Latina; COVID-19; burguesías; derechas

Abstract: The article is an outline of the questions that should be taken into account for a subsequent detailed, extensive and careful analysis of the current political situation in Latin America, which is characterized by a notable and aggressive advancement of right-wing positions at all levels of society.

In terms of the exercise of power, we see the election of capitalists to institutional representation, as occurred during the initial rise of the bourgeoisie as a class. This exercise of power is carried out in a global context dominated by a pattern of capital accumulation based on financial valuation and the simultaneous development of the crisis-signal in the North American systemic accumulation cycle. It has led to a formidably unequal distribution of wealth that, more than fear and/or hatred, shows a formidable disregard for the life of the majority of the world population on the part of the bourgeoisie. This behavior, whose most brutal expression is the desire for the death of "the others," is usually expressed in a generic way, but sometimes refers to specific individuals. Significantly, it is accompanied by the growing influence of the evangelical churches, particularly among the popular classes. The covid-19 pandemic has highlighted the limits of the current capitalist model and has generated the first manifestations of what is supposed to appear once it is over. The author calls for caution and for further research before any forecasts can be made.

Keywords: cconjuncture; Latin America; covid-19; bourgeoisie; right-wing forces 


\section{Brevísimo prólogo}

Una de las dificultades del análisis de coyunturas en curso - momentos de aceleración del tiempo histórico- es que durante el lapso que media entre la escritura y la publicación (salvo que sea inmediata) pueden acaecer acontecimientos que modifiquen sustancialmente, incluso hasta desmentir o contradecir, lo sostenido por el/la analista. A veces, el giro puede ser hasta radical. Hay un momento en que todo analista de coyuntura se siente hermanado con los pronosticadores del tiempo.

En este tipo de análisis es necesario observar algunos criterios explicativos ineludibles: 1) el coeficiente histórico (en los términos de Piotr Sztompka); 2) la historia de larga duración (conforme a Fernand Braudel) de la sociedad en cuestión; 3) la distinción entre movimientos ocasionales, inmediatos (de coyuntura), y movimientos orgánicos, relativamente orgánicos (estructurales), siguiendo a Antonio Gramsci. Es posible que la pandemia de la COVID-19 sea un hecho accidental capaz de devenir orgánico.

Suelen ser momentos en los que es frecuente la aparición de lo que Gaston Bachelard llamaba obstáculo epistemológico, el de la imposibilidad de pensar cuando un cambio de escenario impide la reflexión. Pensamos sobre la base de conocimientos previos (experiencia básica) que nos permiten explicar por qué las cosas son como son. Cuando el escenario cambia, más si es bruscamente, tienden a primar las concepciones espontáneas (percepciones sensoriales del mundo que nos rodea y de la vida cotidiana) y las inducidas (procesos de socialización, en los cuales son fundamentales el entorno familiar $y /$ o social $y$ los medios de comunicación de masas). Esas concepciones obstaculizan reflexionar en profundidad sobre los cambios.

\section{Tiempos de ciclones, tiempos de anticiclones}

Este artículo es una reescritura del inicialmente titulado "Ciclones y anticiclones en América Latina. Una metáfora meteorológica para explicar la actual coyuntura latinoamericana". Estaba revisándolo para su envío cuando la pandemia se universalizó y obligó a cambiar título y contenido. En el original recurría a la metáfora de ciclón y anticiclón teniendo en cuenta que el primero es borrasca y el segundo, tiempo estable. Quería aludir, con ella, a la dinámica de las sociedades latinoamericana a lo largo de las dos primeras décadas del siglo XXI. En términos generales, los tres primeros lustros del siglo xxI — tiempos anticiclónicos- se caracterizaron por la acción, en varios países latinoamericanos, de los llamados gobiernos progresistas, nacional-populares, populistas y hasta de nueva izquierda, 
nunca del todo bien definidos conceptualmente, que prefiero denominar según el viejo pero aún vigente concepto de reformistas. Gobiernos que, sin afectar a las estructuras basales del capitalismo, impulsa(ro)n políticas tendentes a reducir los niveles de desigualad social, redistribuir los ingresos en favor de las clases populares ( $\sin$ despojo de la burguesía) — mediante mejoras de las condiciones de vida de estas con nuevos derechos, tales como acceso favorable a la educación, la salud y el trabajo, tanto para los asalariados en general como para los campesinos, los niños y la tercera edad- y reconocer, más o menos ampliamente, los derechos de las mujeres.

Esos gobiernos reformistas fueron los de Argentina (2003-2015), Bolivia (2006-2019), Brasil (2002-2016), Ecuador (2007-2017), El Salvador (20092019), Honduras (2006-2009), Paraguay (2008-2012), Uruguay (2004-2020) y Venezuela (1999-2013). Como se aprecia, esos gobiernos duraron dieciséis años en Uruguay, catorce en Brasil y Venezuela, trece en Bolivia, doce en Argentina, diez en Ecuador y El Salvador, cuatro en Paraguay y tres en Honduras. Me apresuro a señalar que el caso venezolano, que bajo la presidencia de Nicolás Maduro continúa políticas iniciadas por su predecesor Hugo Chávez, entró en tiempos ciclónicos a partir de la acción desestabilizadora y golpista de la oposición derechista aupada por el imperialismo norteamericano. Es significativo el tiempo de duración de aquellas experiencias: nueve años y medio de promedio, con diferencias notables entre la máxima (16) y la mínima (3). Pareciera que existe, en política, el equivalente al ciclo de Juglar (7-11 años) en la economía. Habría que indagar más al respecto.

Las acciones de los gobiernos reformistas produjeron significativas transformaciones en la distribución de los ingresos, de una magnitud tal que modificaron cuantitativamente la estructura de clases al engrosar a las clases medias, sujeto social mimado por las derechas y los reformistas. Significativamente, esas transformaciones positivas no se tradujeron necesariamente en nuevos triunfos electorales, sino en sonadas derrotas frente a los candidatos de derecha, como indican los casos de Argentina, Brasil y Uruguay, con las victorias electorales de Mauricio Macri (2015), Jair Bolsonaro (2018) y Luis Alberto Lacalle Pou (2019), respectivamente. Chile, aunque con sus particularidades, es otro ejemplo, ya que en las elecciones de 2018 Sebastián Piñera fue elegido presidente por segunda vez (no consecutiva).

Pregunta obvia: si ante acciones de gobiernos reformistas, no anticapitalistas, las burguesías y sus aliados reaccionaron de la manera desaforada en que lo hicieron, desde la judicialización de la política hasta el golpe de Estado (Honduras, Paraguay, Brasil, Bolivia), violando la propia concepción liberal del Estado de 
derecho, ¿qué podría esperarse en el hipotético caso de un proyecto, más o menos viable, de transformación anticapitalista? Puede que no esté en el horizonte, pero ello no invalida plantearse la cuestión. La inexistencia de un sólido proyecto anticapitalista no implica no poder formular la cuestión. Si se renuncia a la utopía, perdemos aquello para lo que ella sirve: para andar.

No se ha reflexionado seriamente sobre las razones de las derrotas electorales de gobiernos reformistas (Argentina, 2015; Brasil, 2018; Uruguay, 2019), pero mi hipótesis es que ellos y las fuerzas políticas a los que pertenecían, aunque lograron sucesivos triunfos electorales, no construyeron hegemonía. Ganar elecciones es una cuestión, construir hegemonía, otra bien diferente. Hoy, desde el pensamiento crítico, hay que reiterar la pregunta formulada por Wilhelm Reich en 1933 ante el avance del nazi-fascismo: ¿por qué en una situación de crisis económica las masas optaron por la derecha, incluso la extrema derecha, y no por la izquierda o, siquiera, el reformismo? Es una pregunta actual.

El quinquenio 2015-2019 (tiempo de ciclones) marcó el avance de las derechas, cada vez más duras. Lo hicieron por vía electoral, excepto en Bolivia y Brasil, aunque en este país luego fueron avaladas electoralmente. En Ecuador, contra todo pronóstico, el nuevo presidente, Lenín Moreno - el candidato nominado por su antecesor, Rafael Correa-, desde la asunción del cargo (2017) comenzó a implementar políticas neoliberales, dando un giro radical a las de Correa. En Brasil, el gobierno derechista de Michel Temer, vicepresidente de la derrocada Dilma Rousseff, fue ungido por el Congreso para completar el mandato de ambos iniciado en enero de 2015. En las elecciones de 2018, el derechista fundamentalista Jair Bolsonaro fue elegido por la vía electoral. En Argentina, el presidente de derecha Mauricio Macri, ganador por la vía electoral en segunda vuelta en 2015, no pudo revalidar su mandato al ser derrotado en la primera vuelta en las elecciones de 2019 por una fórmula reformista continuadora de la fase 2003-2015. En Chile, Sebastián Piñera, presidente entre 2010 y 2014, volvió a serlo en 2018, año en que Colombia optó por Iván Duque Márquez y Paraguay por Mario Abdo Benítez (hijo del secretario particular de Alfredo Stroessner). En 2017, Jovenel Moïse fue elegido presidente de Haití y Juan Orlando Hernández Alvarado consiguió, por escaso margen, ser reelecto para gobernar Honduras entre 2018 y 2022.

En Perú, la renuncia forzada de Pedro Pablo Kuczynski, presidente entre 2016 y 2018 - ante la posibilidad de destitución por acusaciones de actos de corrupción vinculados con la constructora brasileña Odebrecht-, llevó al cargo al vicepresidente, Martín Vizcarra Cornejo. 
En 2019 la derecha avanzó nuevamente al triunfar en El Salvador, Guatemala y Uruguay, llevando a la presidencia a Nayib Bukele, Alejandro Eduardo Giammattei Falla y Luis Alberto Lacalle Pou, respectivamente.

En contrapartida, presidentes considerados dentro del amorfo y vago término de progresismo fueron elegidos en Costa Rica (Carlos Alvarado Quesada) y México (Andrés Manuel López Obrador) en 2018, y en Argentina (Alberto Fernández) y Panamá (Laurentino Cortizo Cohen) en 2019. En República Dominicana, desde 2012 es presidente Danilo Medina Sánchez, cuyo segundo mandato concluye este año (2020), habiéndose suspendido las elecciones previstas para mayo en razón de la pandemia de la COVID-19, la cual seguramente también impedirá las elecciones en Bolivia y con ellas la posibilidad de desplazamiento de la derecha golpista encarnada en la figura de la presidenta usurpadora Jeanine Áñez Chávez, aspirante a ser elegida por la vía electoral (no necesariamente democrática).

Todas esas experiencias tuvieron y tienen lugar bajo el patrón de acumulación del capital basado en la valorización financiera, vigente a escala mundial desde mediados de la década de 1970. Si se prefiere, desde otra perspectiva, la de Giovanni Arrighi, puede decirse que las dos primeras décadas del siglo xxi se despliegan en la situación de crisis del ciclo sistémico de acumulación del capital norteamericano, cuya crisis-señal se dio en la década de 1970. Hoy, el capitalismo norteamericano lucha por postergar el momento de la crisis terminal, una clave para entender el conflicto con China.

Hay analistas que atribuyen el triunfo de las derechas a la conjunción de crisis económicas, más o menos graves, generadas por la caída de los precios de las materias primas exportables, en contraste con el ciclo "progresista", y a los supuestos hechos de corrupción mediáticamente atribuidos a los gobiernos de este signo. De serlo, son insuficientes. Las coyunturas nunca se explican por lo inmediato.

Los avances de las derechas originaron la popular expresión "nuevas derechas", la cual, a mi juicio, da cuenta, amén de otras cosas, del golpe macizo recibido por el pensamiento crítico latinoamericano en los procesos de transición de las dictaduras institucionales de las Fuerzas Armadas a la democracia. Por añadidura, no solo proliferan las nuevas, los nuevos, las y los neo, también los y las pos. ¡Qué degradación del pensamiento!

He escrito antes (Ansaldi, 2017) que lo grave no es referirse a nuevas derechas —en lugar de lo nuevo de las derechas-, sino hacer de ellas sujetos de acción política, una grosería conceptual. Los sujetos de la acción social son las clases sociales, los de la acción política los partidos, las asociaciones de interés, el Estado. Derecha(s) no designa a un sujeto político, remite a una posición política cuya 
base social, históricamente, ha ido ampliándose. Derecha es la posición política de la burguesía, en primer lugar, pero una parte importante de la base social y política de derecha no ha sido ni es burguesa, toda vez que ha penetrado en importantes contingentes de las clases subalternas.

Pier Paolo Pasolini escribió una vez que la burguesía es "una verdadera y precisa enfermedad. Una enfermedad altamente contagiosa: tanto es así que ha contagiado a todos los que la combaten". La burguesía como metáfora de enfermedad es algo que se adecua muy bien a la pandemia actual.

En la mayoría de los análisis de nuestras sociedades, sean de coyuntura o de larga duración, han desaparecido los sujetos de la acción. Perogrullo diría: los sujetos de la acción social son los hombres y las mujeres, usualmente constituidos en clases sociales, que se esfumaron en la catástrofe del pensamiento crítico. Mal que les pese a muchos, las clases sociales y la lucha de clases aún existen, al margen de los cambios fundamentales del último medio siglo y del hecho de que la bipolaridad clásica burguesía/proletariado se haya modificado y que las clases se definan por algo más que su relación con los medios de producción. No nombrarlas no las hace desaparecer de la realidad (Ansaldi, 2018).

$\mathrm{Al}$ convertir a las derechas o a las "nuevas derechas", para decirlo a la moda, en sujetos de la acción se soslayan las clases, escamoteo conceptual que no es reemplazable por Chief Executive Officer. Es tanta la pereza intelectual que la expresión casi siempre queda reducida a la sigla CEO y, como si fuera poco, es reflejo de colonización mental, pues se opta por decir en inglés lo que bien puede decirse en castellano: oficial ejecutivo en jefe, si se quiere ser literal, o los más usuales presidente ejecutivo, director gerente o director general, según se los llame en cada país.

Referirse a clases implica tener una teoría; referirse a ejecutivos (CEO) es abdicar de la teoría. Ya no hay burgueses ni burguesías, ni siquiera la distinción de Joseph Schumpeter entre empresario y capitalista, solo CEO. iQué degradación del pensamiento!

No parece haber conciencia de que la renuncia a los conceptos ocluye toda y cualquier posibilidad de explicar, de hacer inteligible lo que hay por debajo de la realidad, que es siempre aparente. Fue Freud, si no recuerdo mal, quien advirtió que cuando se cede en las palabras se termina cediendo en las cosas. 


\section{Las burguesías adoptan el formato de institucionali- zación capitalista ${ }^{3}$}

Una cuestión nodal del avance político e ideológico de las derechas es el hecho menos advertido por haberse abandonado la perspectiva de clase: como en los lejanos comienzos del capitalismo, las burguesías latinoamericanas han adoptado en amplia medida el formato de institucionalización capitalista - conforme lo define Göran Therborn (1979) —, es decir, el ejercicio del poder del Estado y del gobierno de modo directo mediante los propios burgueses, sean dueños de los medios de producción, empresarios o gerentes. Es un proceso cargado de dificultades, inter alia, porque es una clase (como todas) no homogénea y en su interior las relaciones suelen ser anárquicas, contradictorias (aunque no antagónicas), con intereses diferenciados. La burguesía es una clase numéricamente minoritaria, pero compensa esa debilidad cuantitativa con la formidable concentración de poder disponible, con capacidad para construir hegemonía incluso sobre las clases subalternas. Es una clase que dispone de varios recursos que sabe utilizar muy bien, entre ellos una formidable provisión de talentos. Digo talentos en la doble acepción del término: como capacidad intelectual para desarrollar hábilmente una actividad, y como metáfora de la moneda de la Antigüedad originada en Babilonia y extendida por el mundo del Mediterráneo.

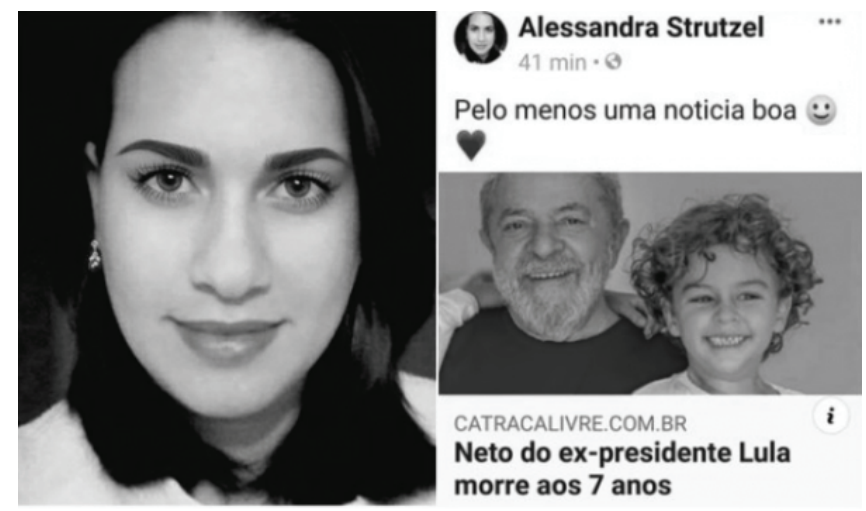

Foto: Reproduçã

Imagen 1. Alessandra Strutzel.

Los burgueses, los empresarios y los gerentes de las empresas capitalistas (incluyendo los bancos y financieras, los grandes triunfadores del patrón de acumulación basado en la valorización financiera) no han tomado o intentan tomar el control directo del Estado para ocuparse de los intereses y negocios del Estado,

3 En este parágrafo retomo, con variantes y añadidos, lo expuesto en Ansaldi (2018). 
sino para consolidar los propios, incluyendo hacer negocios con el Estado mediante el Estado y a costa del Estado. El gobierno de Mauricio Macri es un escandaloso ejemplo perfecto.

La reaparición del formato originario de ejercicio del poder por la burguesía es, básicamente, un fenómeno del siglo Xxi en algunos países latinoamericanos. En la coyuntura actual se incluyen, entre otros, Mauricio Macri (Argentina), Horacio Cartes (Paraguay), Gonzalo Sánchez de Lozada y Samuel Doria Medina (Bolivia), Sebastián Piñera (Chile), Álvaro Uribe Vélez (Colombia), Álvaro Fernando Noboa (Ecuador), Vicente Fox (México), Pedro Pablo Kuczynski (Perú), Ricardo Martinelli y Juan Carlos Varela (Panamá), Jovenel Moïse (Haití), Elías Antonio Saca González y Nayib Bukele (El Salvador). A menudo, reforzando el control del poder, sus ministros son o han sido también capitalistas, empresarios o gerentes (Nercesian y Casaglia, 2019). Obviamente, no han sido ni son los primeros burgueses presidentes. Lo novedoso es que, a diferencia de sus predecesores, que ejercieron el poder bajo otros formatos burgueses de representación (notables, partido burgués, estatismo), los recién señalados son expresión del formato de institucionalización capitalista.

Este formato, apenas puesto en práctica — de manera incluso parcial - en algunas ciudades-república del capitalismo inicial, corresponde a la prehistoria de la democracia burguesa (Therborn, 1979: 224-225). Hoy, las burguesías de América Latina han redefinido o pretenden redefinir los términos de la democracia retrocediendo seis siglos. Así, ella pasa a ser del pueblo (en tanto este le dio legitimidad de origen mediante el sufragio), por la burguesía, para la burguesía. Los gobiernos que, incluso con el voto popular, han gobernado en favor de los intereses burgueses no son una novedad. La novedad radical reside, precisamente, en el por, en quienes tienen el poder y ejercen el gobierno directamente, sin representantes o intermediarios. Ahora bien, el principal problema del formato no reside tanto en garantizar la representación de la clase dominante en ese formato, sino en cómo conseguir la continuidad de ese formato. El caso argentino es un ejemplo de fracaso; el de Chile, de éxito, pero la reacción popular de 2019, frenada por la COVID-19, pone de manifiesto los límites para la continuidad.

Metodológicamente, para precisar el carácter de clase del poder del Estado es necesario dar respuestas a las preguntas qué se hace (eventualmente, qué no se hace) a través de ese poder, y cómo se hace mediante el mismo (Therborn, 1979: 171). Una orientación puede encontrarse en una carta de Friedrich Engels a Albert Sorge (31 de diciembre de 1892): "[... ] hace tiempo ya que los norteamericanos han proporcionado al mundo europeo la prueba de que la república burguesa es la república de los hombres de negocios capitalistas, en la cual la política es un 
negocio como cualquier otro" (en Marx y Engels, 1972: 335-336). Bien podría haber escrito que "la democracia burguesa es la democracia de los hombres de negocios capitalistas", y no habría errado.

\section{Un hijo de puta menos, cinco o seis millones de negros menos $¥$ la muerte (ajena) les sienta bien. El verdadero rostro de las derechas}

El viernes 1 de marzo de 2019, en Santo André, en el cordón paulista, falleció, a los siete años, por una meningitis meningocócica, Arthur Araújo Lula da Silva, nieto del expresidente Luiz Inácio Lula da Silva. La justicia —así se llama, pero es un nombre de fantasía en el Brasil de hoy - del estado de Paraná lo autorizó a permanecer solo una hora y media en el velatorio.

Minutos después de conocerse el fallecimiento del niño, la youtuber brasileña Alessandra Strutzel, una fanática de Bolsonaro, tuiteó una foto del abuelo con su nieto y escribió que se trataba de una buena noticia. Para esta mujer con menos sensibilidad que un escorpión, la muerte del niño era una buena noticia, reforzada por dos elocuentes emoticones: una carita sonriente y un corazón rojo. No terminó allí, pues enseguida, cuando una lectora le preguntó cuál era la buena noticia, respondió: "Un hijo de puta menos". Canallada que la misma lectora le señalará diciéndole que no ha entendido nada, pues quien ha muerto es un niño de siete años. Strutzel no admitió razones y respondió categórica: "Entendí, sí. Piensa, iba a crecer con el ejemplo del abuelo. Un hijo de puta menos para robar nuestro país".

Dejo de lado, ahora como en aquel momento, la indignación ante tamaña inmoralidad, golpe rastrero a la dignidad y a la condición humanas, y lo observo desde otro ángulo, no el de la subjetividad personal, sino el de la explicación propia de nuestro oficio de científicos sociales. Entonces recordé el celebérrimo enfrentamiento entre Miguel de Unamuno y el general José Millán-Astray y Terreros en el paraninfo de la Universidad de Salamanca, el 12 de octubre de 1936. En esa ocasión, los falangistas se exaltaron y se pronunció el terrible grito de "iViva la muerte!".

El episodio es bien conocido, de manera que abrevio, reteniendo tan solo unas pocas consideraciones que hacen al argumento que quiero exponer aquí y ahora. Unamuno respondió que el insensato y necrófilo grito era una ridícula paradoja repelente. Y enseguida, con gran coraje, añadió que Millán-Astray era un inválido de guerra - dato objetivo, pues, en efecto, había sufrido cuatro graves heridas durante la llamada guerra de Marruecos (en el pecho y una pierna, pérdida de 
un brazo y un ojo, destrozo de maxilar)—, como también lo había sido Miguel de Cervantes. Pero el problema, para la España de entonces y para su desgracia, era la existencia de demasiados mutilados. Y si uno solo de ellos carecía de la grandeza espiritual del autor de Don Quijote, lo esperable era que encontrase un terrible alivio viendo la multiplicación de mutilados a su alrededor. La secuencia es conocida. Millán-Astray fue un mutilado cuyo alivio fue el pronosticado por Unamuno.

En abril de 2019, en Argentina, Elisa Carrió, diputada nacional de Cambiemos, en ese momento la coalición gobernante, al conocer la muerte en un accidente del exgobernador de la provincia de Córdoba, José Manuel de la Sota (peronista), expresó: "Gracias a Dios que murió De la Sota". Fue tal la indignación que generó que luego, desde su Twitter, quiso enmendar lo dicho, pero fue "no aclares que oscurece". Meses después arengó a sus partidarios, durante la campaña para las elecciones de octubre, gritando que de Olivos (la residencia de los presidentes argentinos) los iban a sacar muertos (se refería a Macri y los suyos).

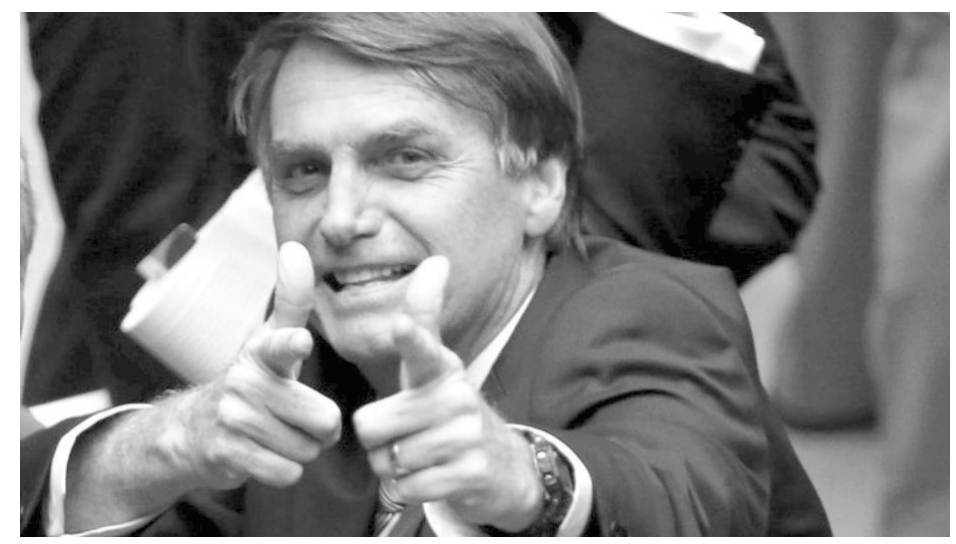

Imagen 2. Jair Bolsonaro.

Durante la misma campaña electoral, Pablo Yapur, candidato a diputado provincial por la fuerza política que buscaba la reelección de Macri, envió a sus potenciales votantes unas consignas centradas en el odio hacia "los putos" y "los pobres" que votaron al Frente de Todos (la coalición que postulaba la fórmula Alberto Fernández-Cristina Fernández de Kirchner, a la postre triunfadora): "ayuda cero" y "que se caguen de frío, que se caguen de hambre y que duerman en la plaza" los "negros sucios, drogadictos, vagos" y "basuras producto de doce años" de kirchnerismo. "Que se caguen porque esos hijos de un millón de putas son los que han votado a este K de mierda", añadió refiriéndose a Sergio Casas, el gobernador lo- 
cal que buscaba la reelección. Ante la masiva reacción negativa a sus expresiones, afirmó que no era su voz (diario Página/12, 27 de septiembre de 2019).

A comienzos de abril de 2020, ya desatada la pandemia y estando Argentina en aislamiento social obligatorio, Julio Carballo, exconcejal de Capilla del Monte (Córdoba) por la coalición macrista, expresó: "En este país, la gente entiende a los palazos, si no, no hay forma. Y como gran parte de este país es peronista, el peroncho [expresión despectiva para referirse a los peronistas] entiende a bala, palo, patada en el culo, es de la única forma. Es negro [... . Lo único que espero es que esta pandemia haga la limpieza étnica que todos nos merecemos. Por mí, que La Matanza [uno de los 135 partidos de la provincia de Buenos Aires, situado en el llamado Gran Buenos Aires, vecino a la capital y con una población que ronda los dos millones de habitantes] le haga honor al nombre y con cinco o seis millones de negros menos, planes [de ayuda social] menos, peronistas menos, capaz que este país arranque". (Diarios y portales de noticias del 6 de abril de 2020 y días siguientes).

En 2018, en Argentina, el presidente, Mauricio Macri, y la ministra de Seguridad, Patricia Bullrich, celebraron y alabaron el asesinato por la espalda de un ladrón de dieciocho años por el policía Luis Chocobar, hasta el punto de recibirlo en el despacho presidencial en la Casa Rosada. Ese gobierno propició la llamada "doctrina Chocobar", un eufemismo para dar a la policía carta libre para matar a delincuentes, reales o presuntos, soslayando los procedimientos legales.

Entre el “iViva la muerte!" de los falangistas y el "Un hijo de puta menos" de Strutzel y las expresiones de Carrió, Yapur y Carballo, la diferencia cualitativa no es menor. El grito en Salamanca era genérico, al igual que los de Yapur y Carballo, mientras que los de Strutzel y Carrió fueron puntuales, específicamente personificados, con el odio dirigido sin hipérbole contra dos personas con nombre y apellido.

Hay que reconocerles la sinceridad. Strutzel dejó claro, explícitamente, que celebra la muerte de un enemigo, no de hoy, sino del futuro (por tanto, potencial), cuando creciera siguiendo, según ella, el ejemplo del abuelo. Yapur y Carballo expresaron algo que he escuchado demasiadas veces en Argentina, en voz baja o no tanto, en lugares de espera y/o de grupos de personas (consultorios, trenes y estaciones, ómnibus y terminales, negocios de barrio, entre otros), voces pidiendo pena de muerte para delincuentes, para "pibes chorros", para personas en "situación de calle", y hasta para manifestantes, cuando no para inmigrantes — ¡en Argentina!, país aluvional como pocos-, sin siquiera preguntarse, muchos menos aceptar, que antes habría que tener en cuenta las condiciones sociales que llevan a hombres, mujeres, niños, adolescentes y jóvenes a situaciones de vida 
tan extremas. No hay que engañarse: los mutilados mentales sobreabundan y son quienes más temprano que tarde terminan apoyando a hombres y mujeres de la política que reclaman mano dura. El triunfo electoral de Bolsonaro no fue un accidente. $\mathrm{Y}$ su actitud gestual de simular disparar un arma de fuego es más elocuente que las palabras.

Hay diferentes formas burguesas de matar sin disparar un solo proyectil. Tres ejemplos que vienen al caso: 1) la pretensión de Donald Trump de fabricar una vacuna contra la COVID-19 solo para los estadounidenses; 2) la decisión del mismo Trump de suspender la cuota de su país para el sostén de la Organización Mundial de la Salud; y 3) la más importante: la acción de las grandes empresas farmacéuticas, que definen la producción o no de determinados medicamentos en función de sus ganancias ${ }^{4}$. Respecto al punto 3, aportaré tan solo cuatro datos, por economía de espacio: 3.1. "La industria farmacéutica ha convertido la enfermedad en un negocio. La globalización ha permitido extender su poder por el que deciden qué enfermedades y qué enfermos merecen cura. El 90\% del presupuesto dedicado por las farmacéuticas para la investigación y el desarrollo de nuevos medicamentos está destinado a enfermedades que padecen un $10 \%$ de la población mundial. En la actualidad [2017] más de 2.000 millones de personas se ven privadas de su derecho a la salud"; 3.2. "El mercado farmacéutico supera las ganancias por ventas de armas o las telecomunicaciones. Por cada dólar invertido en fabricar un medicamento se obtienen mil de ganancias, gracias a que si alguien necesita una medicina y dispone de recursos la compra"; 3.3. "Los márgenes de ganancias de estas industrias son muy importantes alcanzando entre el 70 y el $90 \%$, con una tasa de ganancias del 20\%, superando ampliamente el 15,8\% de los bancos comerciales"; y 3.4. "Dificultan el acceso a la atención sanitaria y a la disponibilidad de medicamentos esenciales a gran parte de la población por su elevado coste que es fijado abusivamente por los laboratorios. Favorece los intereses industriales a expensas de la mayoría de la población. El caso del tratamiento de la Hepatitis C con Sovaldi a un precio brutal es un ejemplo paradigmático".

Sin pretensión de generalizar, pareciera que la COVID-19 actúa de manera discriminada según bandas etarias e indiscriminada según clases sociales o pertenencia étnica. Sí es evidente que no son pocos los casos en los que la discriminación étnica, clasista y/o etaria es claramente apreciable en el tratamiento de los infectados: dejar morir a los ancianos, a los afrodescendientes (como se ha denunciado en los Estados Unidos), a los pobres e indigentes.

4 Véase "La enfermedad, un excelente negocio para la industria farmacéutica", artículo publicado en Nuevatribuna.es el 19 de agosto de 2017, <https://www.nuevatribuna.es/articulo/sanidad/enfermedad-negocio-industria-farmaceutica/20150302105350113131.html Las citas entrecomilladas están tomadas de este artículo>. 
"Hay que matarlos a todos" es una expresión frecuente. Ahora bien, ¿quiénes son todos?". La misma pregunta formula el psicoanalista argentino Sebastián Plut, quien responde: "negros, judíos, homosexuales, chorros, zurdos, y hasta el vaguísimo 'esos". Matar, añade, es expresión de odio y de intolerancia absoluta. "Matar a todos" no solo estigmatiza, sino que incluye dos propósitos: crear un pensamiento desconectado de la realidad y, con independencia de cualquiera de esos grupos a los que se aluda, instalar "negativamente el concepto mismo de todo/s" (Plut, 2018: 191).

"Matar a todos" implica que no debe quedar el antónimo: nadie, ninguno, nada, excepto, claro, los que enuncian matar. Todos son, en realidad, "los otros", genérico que abarca a quienes no son "como uno", no son el Pueblo Elegido. Ahora bien, en buena lógica, matar a todos a la larga supone también la muerte del emisor.

Ellos, "los otros", son objeto de odio, tanto como de miedo, pero también, en otra clave, de indiferencia. Sigmund Freud escribió alguna vez que lo contrario del amor no es el odio, uno y otro expresiones de sentimiento, sino la indiferencia, ausencia total de sentimiento, reducción del otro a la insignificancia, a la nada misma. Ella puede ser más cruel que el odio. Es la impasibilidad ante todas y cada una de las víctimas de tantas maldades humanas y/o sociales: enfermedad, miseria, hambre, tortura, femicidio, desalojos (desahucios en España) y unos cuantos etcéteras. Tal vez por eso la odiaba Gramsci.

Evidencia empírica de la indiferencia es la oposición del sector más concentrado de la burguesía argentina a un proyecto de ley que persigue gravar a las familias más ricas del país, es decir, a las poseedoras de patrimonios superiores a 3.000.000 de dólares estadounidenses (unas 12.000, el 1,1\% del total de los contribuyentes al Impuesto sobre los Bienes Personales, el 0,08\% de la población económicamente activa, PEA), con un $1 \%$ de sus fortunas - buena parte de las cuales fue transparentada por un "blanqueo" de capitales dispuesto en 2017 por el gobierno macrista (del cual el hermano del presidente fue un gran beneficiario) y otra está en guaridas fiscales_-, tributo excepcional que persigue recaudar fondos para atender la emergencia generada por la pandemia en el país. Los burgueses ultramillonarios no solo se oponen a ese minúsculo (para ellos) aporte, sino que, cuando pueden, despiden a trabajadores de sus empresas, como en los casos de Paolo Rocca, del Grupo Techint, el hombre más rico de Argentina, cuya riqueza está estimada (según Forbes) en 9.700 millones de dólares, y Nicolás Dujovne (que fue ministro de Macri), o reducen los salarios.

Mahatma Gandhi sostenía que le horrorizaba más la indiferencia de los buenos que los actos de los malos. Sin ser filósofa, ni científica social ni política, Lady 
Gaga lo ha expresado sintéticamente: "La indiferencia da miedo". Tengo para mí que maldad + indiferencia es una suma de terror. En ese sentido, las acciones y las inacciones de los gobiernos de derecha se explican, a menudo, más por la indiferencia que por el miedo o el odio. En Argentina, Macri prometió "pobreza cero" como resultado de su presidencia; terminó la misma llevándola, en apenas cuatro años, a casi el $40 \%$ de la población del país. Más dramática aún, la reducción de los presupuestos destinados a salud pública — por poner un ejemplo relevante en estos meses de pandemia - ilustra bien lo que quiero decir (en Argentina ese gobierno dejó vencer vacunas, abandonó en galpones o a la intemperie material e insumos médicos y sanitarios...). El caso ecuatoriano es aún peor, y las terribles imágenes de los cadáveres abandonados en las calles de Guayaquil son más elocuentes que cualquier palabra. Ese abandono de la atención de la salud es dramático porque de la pobreza se puede salir, de la muerte, no. Y como canta Mayte Martín, "debajo de la tierra no hay saludo, los muertos no conocen ni a los muertos".

Del "iViva la muerte!" falangista de 1936 al "Un hijo de puta menos" de una bolsonarista en 2019 y a las celebraciones macristas de 2019 y 2020, al desprecio absoluto del presidente Bolsonaro por la salud, es decir, por la vida de sus connacionales, 83-84 años después, ¿qué es nuevo en lo sustantivo del mensaje? ¿Nuevas derechas? ¡Vamos! No me cuenten más cuentos. Terminemos con la pereza mental.

\section{Política y religión ${ }^{5}$}

La crisis de los proyectos laicos - como el del socialismo- no es ajena al reverdecer de los relatos y proyectos religiosos, sea bajo la forma de islamismo o de cristianismo fundamentalistas. En América Latina, este último es el que cuenta. No es un dato de la realidad actual y casi siempre ha sido y lo es de las clases populares.

La relación entre religión y política no es, por tanto, un hecho nuevo en América Latina. De hecho, se remite a los tiempos de la colonia. Lo que es relativamente nuevo es el creciente y decisivo papel de las iglesias evangelistas, algunas de las cuales llevan muchos años actuando, a menudo sigilosamente, en varios Estados, como Chile y Brasil, país que cuenta con el mayor número de fieles del mundo, por detrás tan solo de los Estados Unidos.

Los evangélicos o evangelistas son un conjunto heterogéneo de creencias: bautistas, menonitas (importantes en el campo paraguayo), metodistas, pres-

5 Algunos párrafos de este parágrafo fueron expuestos ya en Ansaldi (2018). Para esta relación, véase Michael Lowy, Guerra de dioses: religión y politica en América Latina. Madrid: Siglo XXI Editores de España, 1999. 
biterianos, protestantes y pentecostales, estos últimos los de mayor crecimiento a escala planetaria. Tienen una larga presencia en Chile, donde en la década de 1960 se los vinculó a la Agencia Central de Inteligencia (CIA), y son una clave explicativa de la política guatemalteca, especialmente por su estrecha relación con el ejército y con el dictador Efraín Ríos Montt.

El triunfo de Bolsonaro no se explica bien si no se tiene en cuenta el papel de esas iglesias. En este sentido, arrojan mucha luz las agudas observaciones de la latinoamericanista franco-tunecina Lamia Oualalou, autora de Jésus t'aime. La déferlante évangélique (Les Éditons du Cerf, París, 2018). Ella analiza el proceso mediante el cual esas congregaciones religiosas se fueron infiltrando en todas las instituciones, ya fueran estatales - gobiernos locales, poderes legislativo y judicial, policías, sistema penitenciario - o de la sociedad civil — particularmente empresas de radio y televisión, como Edir Macedo Bezerra, fundador, en 1977, de la Iglesia Universal del Reino de Dios y uno de los hombres más ricos del mundo, según Forbes, que controla Rede Familia y es socio mayoritario de la principalísima Rede Record-, con un nivel de eficacia tal que ha llevado a los sacerdotes católicos a imitar algunas de sus estrategias, como la de incorporar temas de rock and roll en los templos.

Toda la vida cotidiana ha empezado a transformarse: la Coca-Cola, "bebida del diablo", es reemplazada por la Judá Cola, cuya receta ha sido dictada por el Espíritu Santo; las radios proclaman “ذJesús te ama!", la televisión difunde telenovelas con contenido religioso; la policía ha modificado el mandamiento "No matarás" por "Dios retira la vida. Solo estoy apretando el gatillo". En el Congreso, las sesiones se interrumpen para orar... Los pastores han devenido líderes en el seno de la sociedad civil y han ganado y ganan cargos políticos electivos. No se trata tampoco de un suceso inesperado. Ya en las elecciones de 1989, donde los medios de comunicación hicieron campaña sucia contra la candidatura presidencial de Lula, los grupos evangelistas jugaron un papel decisivo en el triunfo de Fernando Collor de Mello. Pero antes hubo evangelistas, sobre todo pentecostales, que, pese a su anticomunismo, apoyaron al Partido de los Trabajadores (PT) en 1989 y luego entre 2002 y 2014. Una de sus figuras más relevantes, Benedita da Silva, ha tenido una destacada carrera política, precisamente, en el PT.

Las iglesias evangelistas han reemplazado la teología de la liberación por la teología de la prosperidad, cuya lógica es, señala Oualalou, interiorizar en los fieles la convicción de que tienen derecho a todo - a la buena vida material, a la salud- en esta vida, no en la próxima." $Y$ si no lo tiene ya es porque no sabe exigir", un giro en el modo de concebir y practicar la relación con Dios, que tiene que conceder aquello, para lo cual "solo tienes que saber pedírselo. Y para 
pedírselo debes formar parte del grupo evangélico, pagar y rezar". Así, "la gente solo escucha la radio evangélica, ve la televisión evangélica, acude a los grupos evangélicos de Facebook y WhatsApp [...], vive encerrada en ese mundo". No extraña, entonces, que lograran imponer una retórica según la cual "la crisis y la recesión son culpa de Satanás, y ese Satanás es el PT".

La Iglesia Universal del Reino de Dios se está expandiendo, sobre todo en Argentina y Chile, y su programa televisivo "Pare de sufrir" se emite a toda América Latina y está ganando espacio en canales de televisión. Por ahora, su inserción en la política está lejos de lo logrado en Brasil.

Un caso particularmente interesante es el de Costa Rica - país que, al igual que Argentina, no ha separado la Iglesia del Estado, cuyo culto este sostiene-, donde un cuarto de la población se define como protestante. En este país se constata la fuerte presencia política de Restauración Nacional, agrupación de corte evangélico que, aunque en las elecciones presidenciales de 2014 obtuvo apenas 27.691 votos (1,35\%), en las de 2018 los multiplicó por 18 , logrando 505.214 votos $(24,91 \%)$ y con ellos el primer puesto, aunque insuficiente para alcanzar la presidencia, pues no obtuvo el $40 \%$ mínimo exigido por la Constitución. En la segunda ronda fue derrotada.

La pandemia de la COVID-19 ha puesto a varias iglesias evangélicas en un lugar relevante, peligrosamente favorable a la propagación del virus, en algunos casos en directa connivencia con el poder político. Obviamente, Brasil en primer lugar. A comienzos de abril, Bolsonaro pidió a los brasileños que el domingo 5 participaran en un ayuno religioso para espantar el virus. La invitación fue apoyada por varios pastores evangélicos, que la consideraron "santa proclamación" y pretendieron hacer la "mayor campaña de ayuno y oración vista en la historia de Brasil”. El vídeo de propaganda mezclaba imágenes y testimonios de pastores con versículos de la Biblia que aluden a Dios como el gran guerrero ${ }^{6}$.

En Cochabamba, Bolivia, el alcalde la ciudad, José María Leyes, presentó el 27 de marzo en el Concejo Municipal un proyecto para declarar la emergencia sanitaria. La disposición reza: "Como pueblo nos sentimos arrepentidos por nuestro pecados y maldad, por lo que pedimos perdón de Dios, convocando a toda la población de Cochabamba a Ayuno y oración durante este tiempo de cuarentena y declaramos que el único que puede ayudarnos y librarnos de esta pandemia es Dios, ya que queda claro que la ciencia del hombre es insuficiente" ${ }^{\text {"7 }}$.

6 <https://tn.com.ar/internacional/coronavirus-jair-bolsonaro-convoco-un-ayuno-religioso-para-superar-la-pandemia_1057341>.

7 <https://www.lostiempos.com/actualidad/cochabamba/20200328/proyecto-ley-municipal-pide-cochabambinos-arrepentirse-sus-pecados $>$. 
En Venezuela, la Conferencia Episcopal del país solicitó al gobierno autorización para realizar procesiones pese a la COVID-19 y la cuarentena.

En la misma línea, pero atendiendo al ámbito doméstico, la Catedral Evangélica de Chile se permitió dar "Consejos para la mujer" a tener en cuenta durante los días de la cuarentena, para "[q]ue el Covid-19 no traiga el caos ni el desorden a tu hogar". Los consejos son apenas cuatro: sé paciente, sé atenta, no discutas, mantén la higiene. Ninguno de ellos parece tener en cuenta que las mujeres del siglo xxi no son las del xvi (y algo más). 1. "Se paciente. El hombre no está acostumbrado a encerrarse en el hogar, puede desestabilizar su temperamento y caer en descontento. Mantén siempre la actitud positiva y pacífica". 2. "Sé atenta. Toda tu familia requiere de tus cuidados y atenciones. Evita perder el tiempo en telenovelas, Facebook o mirando aves por la ventana. Hoy más que nunca tu labor de ama de casa es vital para la subsistencia”. 3. "No discutas. Bastantes problemas ya hay en el mundo como para que tu esposo tenga uno más. Sé cordial en todo momento y evita entrar en temas de conversación polémicos". 4. "Mantén la higiene. El aislamiento casero no excluye que dentro del hogar sigan existiendo plagas o infecciones por la falta de limpieza. Recuerda que un hogar limpio habla muy bien de su ama de casa".

Una pandemia de la magnitud de la COVID-19, que algunos han equiparado con la peste negra que asoló Europa en el siglo xiv, potencia acciones manifiestamente antagónicas y excluyentes, lo mejor y lo peor de los seres humanos. En Argentina, en varias ciudades del país, todas las noches, a las 21.00 horas, se escuchan durante unos cinco minutos aplausos desde las ventanas y balcones de las casas para homenajear al personal de salud que combate el virus. En contraste, no pocos médicos, médicas y enfermeras son objeto de amenazas, de peticiones de irse de su vivienda por el miedo de sus vecinos a ser contagiados, llegándose, como en la ciudad de La Rioja, a quemar el vehículo de una médica infectada. También en México se han reportado numerosas agresiones a enfermeras.

No debería sorprender, ya que en la tradición judeo-cristiana quienes padecen enfermedades de tal gravedad deben ser estigmatizados, humillados y apartados. Es un mandato bíblico que se recoge en el Levítico (13:45 y 46), el tercero de los cinco libros atribuidos a Moisés, parte tanto de la Torá como del Pentateuco: "Y el leproso en quien hubiere llaga llevará vestidos rasgados y su cabeza descubierta, y embozado pregonará: ¡Inmundo! ¡inmundo! Todo el tiempo que la llaga estuviere en él, será inmundo; estará impuro, y habitará solo; fuera del campamento será su morada”.

8 <https://www.resumenlatinoamericano.org/2020/04/14/chile-consejos-ultra-patriarcales-de-los-evangelicos-para-la-cuarentena-en-casa/> 
En el plano político internacional, la postura de China y la de Cuba, que en materia de ayuda con médicos y equipamiento sanitario no han hecho ni hacen distinciones ideológicas, contrastan con la de los Estados Unidos, que ha realizado desplazamientos militares con objetivos poco claros, que, según algunos analistas, apuntan a la pretendida intervención armada en Venezuela o, al menos, a impedir la entrada de insumos médicos y alimentos a un país que, por si fuera poco, a la crítica situación económica ha añadido el desplome de los precios del petróleo, su principal fuente de recursos económicos. A eso se suman las maniobras para impedir la rápida llegada de insumos médicos donados a Cuba por el Alibaba Group, un poderoso consorcio privado chino dedicado al comercio electrónico.

Al mismo tiempo, una situación irónica se produjo a bordo del USS Theodore Roosevelt (que lleva el nombre del presidente que invadió Cuba en 1898), un superportaaviones nuclear (a diciembre de 2019 había 22 en todo el mundo), con 4.398 marineros a bordo, de los cuales, al 23 de abril, 840 (el 17\%) se habían contagiado de coronavirus ${ }^{9}$. Nunca, sin haber recibido un solo disparo, un monstruo militar como este había tenido tantas bajas.

\section{Crisis,++, ¿qué crisis?}

Crisis es una palabra de uso frecuente, acrecentado en estos meses de pandemia. Tal vez por eso, como concepto no suele ser definido, en el sobreentendido de que emisor y receptor saben de qué están hablando. Lo explícito es preferible a los sobreentendidos, de manera que me permito señalar qué entiendo por crisis, inspirándome en Julien Freund. Para los antiguos griegos, la palabra designaba el momento culminante de una enfermedad. Vaya casualidad... Se trata de estados o momentos dentro de un desarrollo temporal, con un comienzo y un final, sin un patrón de duración previsible. En una situación de crisis se expresan contradicciones y rupturas, tensiones y desacuerdos, de una intensidad tal que los sujetos - individuales y colectivos - vacilan respecto de las decisiones a tomar, el camino a seguir y las acciones a realizar, al tiempo que las normas, las reglas $y$ las instituciones hasta entonces existentes dejan de ser observadas y reconocidas, en mayor o menor medida, llegando, en el límite, a ser concebidas como un obstáculo para el desarrollo de la sociedad, al tiempo que las nuevas propuestas no terminan de ser elaboradas o, estándolo, no son asumidas como eficaces y/o pertinentes. Así, las grandes crisis definen momentos históricos en los cuales, como decía Antonio Gramsci, lo viejo no termina de morir y lo nuevo no termina de

9 Véase <https://aristeguinoticias.com/2404/mundo/con-covid-19-840-marineros-del-portaaviones-roosevelt-de-eu/> 
nacer. Ambigüedad e irresolución ponen de relieve ese componente fundamental de toda crisis que es el tiempo.

Las crisis son fenómenos históricos usuales, mas la conjunción o soldadura de crisis económica, social y política no lo es tanto. Menos frecuentes aún son las crisis de mayor intensidad, las que Gramsci llamó crisis orgánicas, cuya característica esencial es la de ser crisis de hegemonía. Es una crisis de autoridad de la clase dirigente, que deviene solo dominante, y de su ideología, de la cual las clases subalternas se escinden. En una crisis tal, la capacidad de reacomodamiento de la clase dirigente o dominante es mayor y más rápida que la de las clases subalternas. Ello le permite -incluso realizando sacrificios y/o formulando propuestas demagógicas - mantener el poder, reforzarlo y emplearlo "para destruir al adversario". La crisis orgánica también puede resolverse por la iniciativa política directa de las clases subalternas, que producen una solución orgánica. Una tercera posibilidad es la del jefe carismático, resultado de un equilibrio estático entre las fuerzas conservadoras y las progresistas, ninguna de las cuales tiene la fuerza necesaria para vencer.

En la historia del capitalismo, la crisis más importante ha sido la de 1929. Fue económica, social, política, de valores, soldadura de dos o más de ellas y hasta crisis orgánica. En los países latinoamericanos, la crisis política fue más de dominación que de hegemonía. Como se sabe, el capitalismo se recompuso, en buena medida dejando de lado algunos de sus principios fundamentales. El New Deal norteamericano, los Estados de bienestar europeos, las propuestas keynesianas fueron parte de la superación de la crisis, cambio en la estructura sin cambio de estructura. Hoy, la pandemia de la COVID-19 visibiliza una crisis más, la sanitaria, que se hace más brutal cuando los ministerios de salud, como en Brasil y Bolivia, son ocupados por personas vinculadas o pertenecientes al sector privado (negocios) de la salud.

En el caso latinoamericano, la desarticulación de organizaciones de integración como la Unasur ha impedido una eficaz coordinación de la lucha contra la pandemia, la cual podría haber permitido consensuar estrategias, aunar esfuerzos y solidaridades y, posiblemente, reducir el número de infectados y de muertos.

Slavoj Žižek dice, con razón, que la pandemia de la COVID-19 ha desencadenado "grandes epidemias de virus ideológicos que estaban latentes en nuestras sociedades: noticias falsas, teorías de conspiración paranoicas, explosiones de racismo" (en Agamben y otros, 2020: 21). Desde que el texto fue escrito, en febrero de 2020, hasta hoy, esas "epidemias ideológicas" se han expandido incluso más que el propio virus, particularmente la difusión de noticias falsas. La lucha contra el virus es médica, política e ideológica, combinación que le otorga una importancia exponencial. 
No son pocos los que señalan que la COVID-19 ha puesto en crisis $y$ ha mostrado las debilidades y los límites de la globalización llamada neoliberal. Es posible. Pero no debe perderse de vista que la globalización es consustancial a la expansión capitalista, como bien lo han demostrado Immanuel Wallerstein y Aldo Ferrer. Comenzó en los siglos Xv-Xvi y uno de sus primeros efectos fue la importación a América de la gripe (1493), el sarampión (1510-1520) y la viruela (década de 1540) por los conquistadores españoles, primero, y después por los ingleses y holandeses, que, por añadidura, lo hicieron deliberadamente en Massachusetts, infectando y matando a los pobladores originarios mediante mantas contaminadas con el virus de la viruela, como afirma Agustín Muñoz Sanz. Por si fuera poco, el comercio de esclavos realizado por los europeos llevó de África a América la malaria y la fiebre amarilla ${ }^{10}$. En menos de un siglo, la población autóctona americana pasó de los ochenta millones estimados a apenas tres millones y medio, una reducción brutal. Convendría no olvidarlo.

Ya hay quienes están pensando escenarios posibles tras el fin de la pandemia. El debate europeo - parte del cual ha sido reunido en un libro con título y tapa desafortunados: Sopa de Wuhan - es uno de los tantos que se irán produciendo, oscilando los pronósticos entre el derrumbe del capitalismo - sería una fenomenal ironía de la historia que la COVID-19 termine siendo su sepulturero-y su recomposición. Seguramente habrá escenarios posiblemente muy conflictivos, en el marco de los cuales no faltarán proyectos de extrema derecha, incluso con pretensiones totalitarias. La lucha de clases se resignificará, en el límite como guerra de clases. La potencialidad del capitalismo para superar sus crisis más fuertes no es una novedad, y hoy, por añadidura, no existe un modelo alternativo de sociedad. Que no lo haya hoy no significa que no lo haya mañana.

En América Latina - continente de tiempos o temporalidades mixtas, como señalamos hace más de treinta años (Ansaldi y Calderón, 1987) - existen especificidades nada desdeñables: situación de dependencia, complejidad de las relaciones étnico-clasistas, modalidades diferentes de las articulaciones entre Estado y sociedad civil, entre otras. Pensar la pospandemia desde la periferia dependiente es un desafío aún mayor que en el centro. Prefiero ser cauto y hacer mías unas palabras de Antonio Machado, cambiando el "español" del original por "humano": "Si cada humano hablase de lo que entiende, y de nada más, habría un gran silencio que podríamos aprovechar para el estudio".

10 Muñoz Sanz es actualmente profesor de Patología Infecciosa de la Universidad de Extremadura y vicepresidente de la Academia de Medicina. Vide <https://wwwagenciasinc.es/Entrevistas/La-viruela-y-el-sarampion-fueron-perfectos-aliados-en-el-exito-de-conquista-espanola-de-America $>$. 


\section{Post scriptum}

Entre la conclusión de la escritura de este artículo y su publicación han mediado nueve meses, demasiado para una coyuntura, y hoy debería ser reescrito a la luz de todo cuanto ha acontecido en ese lapso, lo que escapa a las normas editoriales. Por tal razón, tan solo enumeraré ocho cuestiones que merecen un tratamiento detenido que escapa a las posibilidades de este artículo: 1) la pandemia se ha expandido por todo el mundo y en el último trimestre de 2020 se ha recrudecido (segunda y tercera olas), incluyendo mutaciones del virus, particularmente en Europa; 2) en la mayoría de los países (no solo latinoamericanos), las fuerzas políticas de derecha han minimizado la importancia de la pandemia y han privilegiado la economía sobre la vida, con resultados negativos en una y otra, y esa postura se ha traducido en resultados adversos allí donde ha habido elecciones (Bolivia, Chile, incluso Brasil, donde han ganado fuerzas de derecha no ultra y algo más sensibles) y en manifestaciones masivas (Perú, Guatemala); 3) la "carrera" por obtener vacunas seguras ha mostrado otra vez el poder de las grandes corporaciones farmacéuticas y es uno de los aspectos a tener en cuenta en la campaña contra la rusa Sputnik V, elaborada por el Centro Gamaleya, que no es parte de aquellas; 4) por añadidura, la vacuna rusa y las cuatro chinas (puede sumarse la cubana, que tiene menos prensa) han hecho reaparecer prejuicios y consignas anacrónicos, típicos de los tiempos de la "guerra fría”, absurdos en el caso de Rusia, que hace tres décadas se tornó capitalista; 5) la desigualdad económica y social se ha acentuado dentro de cada país y a escala planetaria, con algunos grandes beneficiarios y miles de millones de seres humanos afectados negativamente, por decirlo con delicadeza, ratificando uno de los peores rasgos del capitalismo; 6) una deriva de ese incremento de la desigualdad atañe directamente a la cuestión vital del acceso a las vacunas, que afecta especialmente a los países más pobres y ha generado la iniciativa de la Plataforma Covax, avalada por 172 Estados (de los 194 soberanos reconocidos por la ONU) y encaminada a lograr la vacunación de toda la población del planeta; 7) la derrota de Donald Trump — un fundamentalista de la negación de la pandemia (igual suerte corrió su émulo subdesarrollado, Jair Bolsonaro) - en los comicios presidenciales norteamericanos; 8) las resoluciones del 19. ${ }^{\circ}$ Plenario del Comité Central del Partido Comunista Chino, ad referendum de la Asamblea Nacional, que implican un giro estratégico que afectará a la economía de todo el mundo en mayor o menor medida.

En el entretanto, la abuela aún resiste. 


\section{Bibliografía}

Agamben, G. y otros (2020). Sopa de Wuhan. s.l. Editorial ASPO (Aislamiento Social Preventivo y Obligatorio), edición digital. La compilación fue realizada por Pablo Amadeo, profesor de la Universidad Nacional de La Plata, Argentina. Puede descargarse desde varios sitios.

Ansaldi, W. (2017). "Arregladitas como para ir de boda. Nuevo ropaje para las viejas derechas". Revista THEOMAI, (35), primer semestre, (22-51). Disponible en línea: <http://www.revista-theomai.unq.edu.ar/numero35>.

Ansaldi, W. (2018). "Aquellos polvos trajeron estos lodos". Disponible en línea: <http://www.espacio-publico.com/involucion-en-america-latina\#comment-6120>.

CEPAL (2020, 21 de abril). "Informe Especial COVID-19. Dimensionar los efectos del COVID-19 para pensar en la reactivación". Disponible en línea: <https://www.cepal.org/es/publicaciones/45445-dimensionar-efectos-covid-19-pensar-la-reactivacion?utm_source=CiviCRM\&utm_medium=email\&utm_campaign=20200422_segundo_informe_covid19>

Ansaldi, W. y Calderón, F. (1987)."Las heridas que tenemos son las libertades que nos faltan. Derechos humanos y derechos de los pueblos en América Latina y el Caribe". David y Goliath, XVII (52), 63-69.

Marx, K. y Engels, F. (1972). Materiales para la historia de América Latina. Córdoba: Cuadernos de Pasado y Presente 30.

Nercesian, I. y Cassaglia, R. (2019). "Presidentes empresarios en América Latina (2000-2019). Un estudio comparado sobre el perfil de los gabinetes". Observatorio Electoral de América Latina OBLAT. Informe núm. 1. Buenos Aires: Facultad de Ciencias Sociales, Universidad de Buenos Aires. Disponible en línea: <http://oblat.am/uploads/images/22ad25d8-a2ac-4f11a746-b4e35740b32.pdf >

Plut, S. (2018). El malestar en la cultura neoliberal. Buenos Aires: Letra Viva.

Therborn, G. (1979). ¿Cómo domina la clase dominante? Aparatos de Estado y poder estatal en el feudalismo, el socialismo y el capitalismo. Madrid: Siglo XXI de España Editores. 